\title{
Development and Validation of a Survey Instrument to Build Capacity for Examining Constraints to Sport Participation
}

\section{Irmina Klicnik, Samah Mohammed* and Caroline Barakat}

Faculty of Health Sciences, Ontario Tech University, Canada

*Corresponding Author: Samah Mohammed, Faculty of Health Sciences, Ontario

Tech University, Canada.
Received: April 15, 2021

Published: May 14, 2021

(C) All rights are reserved by Irmina Klicnik. et al.

\section{Abstract}

It is well documented that sport participation is relatively low among adolescent girls due to various constraints. Though much knowledge exists on these constraints, there is a need to examine if and whether constraints interact to influence sport participation. The purpose of this study was to develop a survey instrument to facilitate the examination of interactions of constraints to sport participation among adolescent girls, and to verify the survey's validity. Two theoretical frameworks were combined to guide the survey development. Newell's model of constraints was used to categorize constraints, into environmental, individual and task constraints. The 40 Developmental Assets Profile was used to index the constraints into broader categories within each constraint type. In total, 51 constraints were sorted into the combined frameworks which developed an 81-question survey. An expert panel was consulted to review for construct and content validity. This study has contributed a new survey instrument to the literature on constraints to sport participation. When used in different locations globally, the survey has the potential to reveal the most salient constraints, as well as build capacity for research to better inform future interventions and promote further discussions regarding sport.

Keywords: Sport; Interactions; Survey Development; Newell's Model; Girls

\section{Introduction}

In Canada, females participate in sport less frequently than males at every age, with the sharpest disparity beginning in adolescence [1]. As a result, there has been substantial interest in exploring constraints for non-participation in sport among girls. This is mainly due to the multitude of benefits accrued though participation in sport, including the positive linear relationship with physical activity level at adulthood [2,3] and the subsequent health benefits. Recent findings also suggest that analysis of constraints to sport participation at the community level is needed to inform long term planning initiatives to increase participation [4].
This is because constraints to sport participation have been shown to vary across geographical regions due to variability in provision of resources [5-7], and geographical variations in socioeconomic status $[4,8]$. As a result, it is important to examine constraints to sport participation in order to address the challenges faced among female populations and promote overall participation in sport.

Due to the wide-ranging nature of human behavior, quantitative measures of constraints to sport participation have yielded mixed results, so a qualitative [9-11] or mixed method approach [12] has been the preferred method of examining constraints to sport participation. In studies where quantitative methodologies were used, 
survey instruments are either modified versions of an established tool $[13,14]$ or an altogether novel tool [15-18]. In both cases, the tools being used are tailored to a specific population or sport and lack generalizability in different settings [18]. Differences also exist in the types of constraints elicited in quantitative versus qualitative studies. According to Charlton and colleagues, quantitative methodologies are preferred to ascertain the role of personal circumstances and external factors, while qualitative methods more accurately describe the underlying psychological (individual) constraints [19].

In addition to the inconsistencies related to the methods used to examine constraints to sport participation, studies have failed to examine potential interactions between constraints and how these impact participation in sports. Much of the research into constraints uses a hierarchical or ecological framework for classifying constraints $[20,21]$. Specifically, the hierarchical model of leisure constraints developed by Crawford and colleagues [20] and ecological frameworks based on Bronfenbrenner's ecology of human development model which have been applied to the study of health behaviors such as sport participation [21,22]. Although use of these frameworks has generated more knowledge about the types of constraints to sport participation that adolescent girls face, the frameworks do not lend themselves well to the examination of interactions. This is acknowledged in the limitations of many studies, which endorse further investigation into the way constraints affect each other $[23,24]$.

The acknowledgement that the components of both the hierarchical and ecological models do affect each other is the key step in moving toward a more comprehensive understanding of the relationship between girls and sport. This study has three main objectives. The first is to review constraints to sport participation identified in literature for adolescent girls and create a comprehensive list of constraints, thus ensuring construct validity. The second objective is to use a conceptual model derived from Newell's model of constraints [25] and the developmental assets profile [26] to organize the constraints and develop a survey that collects data on constraints to sport participation. The third objective is to assess the survey's content validity through consensus building.

\section{Framework}

In previous literature, the hierarchical model of leisure constraints developed by Crawford and colleagues was used to categorize constraints as intrapersonal (psychological states and attributes), interpersonal (based on interactions with others) or structural (externally imposed constraints) [20]. The ecological model elaborated on the structural component by adding institutional, community, public policy, and physical environment constraints. Both models imply that although constraints are related, they are separate; thus, interactions are not considered per se. However, due to the complex nature of human motivation and behavior, a nested model is not sufficient in capturing fluctuating constraints. As it pertains to positive youth development, the creation of interventions to improve outcomes for adolescents often uses a Developmental Systems Theory approach. This approach is based on the understanding that development happens as a result of interaction between an individual and the context in which they develop [27].

A tool for measuring interactions of constraints to sport participation requires a conceptual framework which can facilitate this type of exploration. Though it was developed for the study of motor development in children, Newell's model of constraints lends itself well to the incorporation of both the hierarchical and ecological models used in the past for categorizing constraints (Figure 1) [25]. Based on Newell's definition, a constraint can be reduced or intensified in the presence of other constraints. According to Newell, optimal behavior is the product of the interaction between individual, environmental, and task constraints. Specifically, individual constraints refer to structural or functional factors such as height or motivation. Environmental constraints refer to the broader social context which affects development, including geographical area, the physical environment, sociocultural environment, policies, and the influence of important figures in persons' lives, such as coaches, family, and friends. Task constraints refer to the demands of the activity or sport, and include strength, speed, agility, flexibility, or technical ability, as well as the goals, rules, and structure of an activity (e.g. individual vs. team sport). Task constraints are not considered in hierarchical or ecological models, which signifies a gap in the research on constraints to sport participation. However, both task and environmental constraints constitute the context of an individual's experience and are therefore necessary to include in examinations related to sport participation. In this dynamic model, constraints interact to restrict or facilitate an outcome, in this case sport participation. 


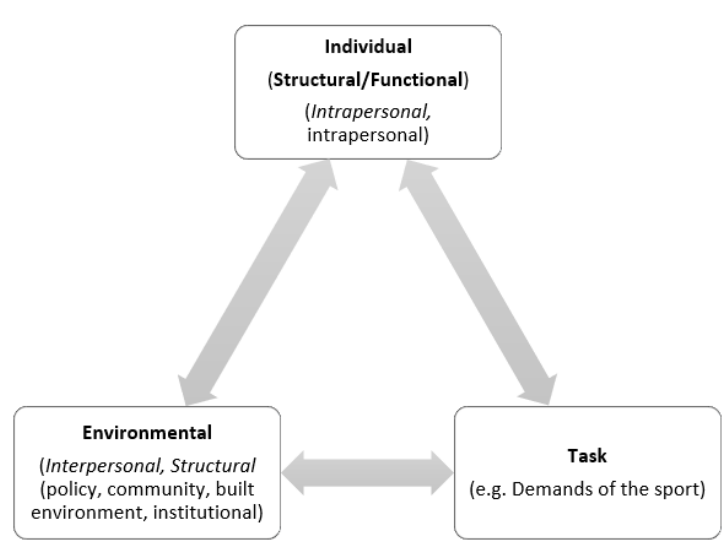

Figure 1: Newell's Model.

Figure Newell's (1986) model of constraints (bolded), modified to include hierarchical and ecological models superimposed.

Bidirectional arrows indicate interactions between constraint types. Constraints in italics are derived from the hierarchical model, and those in plain text incorporate the ecological model.

In addition to Newell's model of constraints, the 40 Developmental Assets Profile [26] is another useful framework with the potential to aid in classifying constraints to sport participation. The development assets profile is an empirically based framework which recognizes that there are many interacting parts to a whole person which cannot be addressed individually to stimulate changed behavior. In recognizing that problems faced by adolescents are usually related to each other, this framework proposes that by increasing the power of 40 internal and external "assets", adolescents will experience better outcomes in physical health and school success, as well as engage in fewer risky behaviors such as drinking and violence [26]. The development assets profile is a holistic framework used in youth development research and interventions [26], and as such, is an appropriate complement to Newell's model [25] in this study. The framework comprises 20 internal and 20 external assets which are based on adolescents' positive experiences with their environment and social network.

\section{Materials and Methods}

\section{Survey construction}

In order to synthesize evidence on constraints to sport participation among adolescent girls, a literature review was completed.
International literature (excluding languages other than English) from 1990 to 2017 which focused on constraints to sport participation was included. Older studies were included to capture constraints related to social norms which develop over long periods of time and change incrementally. Initial search terms from PubMed and CINAHL databases used to compile a list of constraints for our sample were sport, sport participation, barrier or constraint, Canada or Canadian, adolescents or teenagers or young adults, female or girls, and trends. Exclusion criteria consisted of articles which were not peer-reviewed, or those which contained any of injury, trauma, disorder, illness, mental illness, spine, spinal, vertebral, athlete and male or boys in the title.

Based on the findings from the literature review, constraints were categorized using Newell's model. Since Newell's model [25] has not previously been used to analyze constraints to sport participation, parallels were drawn between the model and the more commonly used ecological and hierarchical models as seen in figure 1 . The remaining constraints generated from the review were sorted conceptually into one of the three categories from Newell's model [25]. This iterative process began with evaluating each constraint separately to determine if it logically satisfies the requirements of individual or environmental constraints. After sorting each constraint, the list was reviewed by the expert panel for consensus.

As outlined in the modified version of Newell's model above, individual constraints included any constraints from the literature which related to a person's structure (e.g. anthropometrics) and function (e.g. personal characteristics related to one's development, one's values, identity). Certain aspects of demographics were also considered as individual constraints, if they pertained directly to the individual, rather than their environment. Environmental constraints included any constraints from the literature related to factors external to an individual. Based on the modified Newell's model in figure 1, these were categorized in the literature as interpersonal or structural for Hierarchical and Ecological models, respectively. If no framework was used in the studies consulted in the literature review, any constraints external to an individual but not related to the demands of a sport were included in the Environmental category. Lastly, task constraints were recategorized in consultation with experts in Newell's model [25] as well as sport literature. Additional task constraints were generated using the definition of sport which guided this study [1]. 
After constraints were sorted, an item bank was generated in preparation for survey construction and to verify the validity of the instrument. The survey was expected to have construct validity because the constraints were generated from peer-reviewed literature, and subsequently content validity was generated through consensus building among a panel of experts. A minimum of 5 people is recommended to review an instrument to rule out the possibility of chance agreement [28], thus the panel consisted of a convenience sample of 7 individuals. The constraint list and item bank were circulated among three experts in the field of adolescent sport or with experience in the application of Newell's model of constraints, 2 graduate students, and 2 community members (youth counselors at GIRLS Inc) prior to seeking school board ethics approval. After the survey was drafted, input was also sought from the Durham Catholic District School Board (DCDSB) throughout their Research Ethics application process. The completed survey was again sent out to the panel, who were asked to respond if they felt that any questions were unnecessary.

\section{Results}

\section{Review and classification of constraints}

Though a systematic review is outside the scope of this study, a similar approach was used in searching the literature. Figure 2 is a flowchart based on the Preferred Reporting Items for Systematic Reviews and Meta-Analyses (PRISMA) to illustrate the search process [29]. An integrative review of qualitative and quantitative constraints literature was completed and included Canadian and international literature from 1990 to 2017. The preliminary EBSCOhost search included sport, adolescent or youth or teen or young adult and women or girls or female yielded 4085 articles. However, after excluding based on the exclusion criteria, this was reduced to 165 , and with the addition of barriers or constraints 8 articles remained. Due to the limited volume of articles, a search of grey literature included reviewing the reference lists of these articles to capture constraints which may not have been significant in the research article but were considered during their respective literature reviews. Twenty studies were consulted to generate a list of 51 constraints to sport participation among adolescent girls (Table 1). Of these, 6 (30\%) had used either an ecological or hierarchical model to categorize constraints. The prominence of individual and environmental constraints is consistent with current literature which often uses an ecological framework for examining constraints [21].

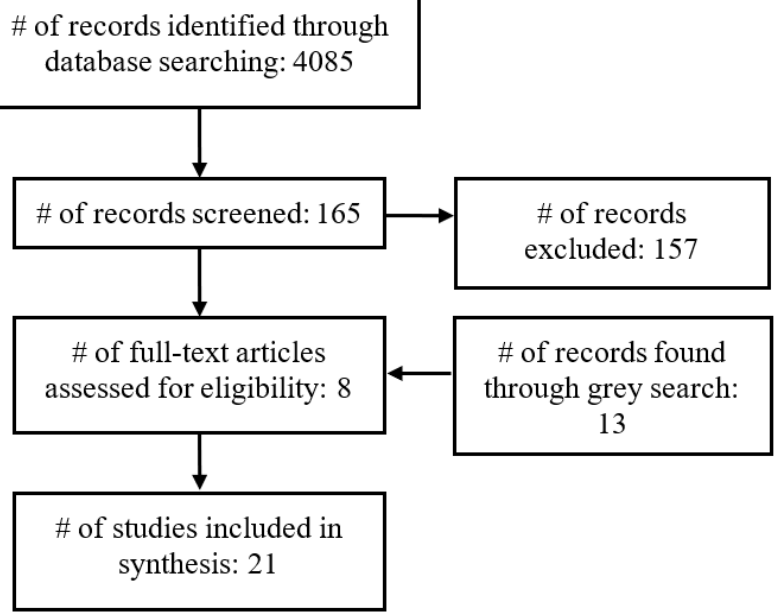

Figure 2: Flowchart of selection process for articles on constraints to sport participation among adolescent girls.

Regarding the categorization of constraints, the constraint list was sorted into 25 individual constraints, 22 environmental and 4 task constraints. Table 1 shows the final breakdown of constraints. of the 51 constraints, 12 (24\%) had been reported in two or more studies. The concept of task constraints was not considered in any literature which used a hierarchical or ecological model of constraints. Only one task constraint appeared in the literature review (competitiveness), and it was contrasted with the opposite (recreational), though this was not a focus of that study [10]. Additional task constraints were added in consultation with the expert panel. Due to a shortage of previous examination, the task constraints were not validated previously. Thus, construct validity was established with input from the experts.

\section{Survey instrument}

The survey was created using Google Forms, which has secure data storage capabilities. A total of 81 items were included, each corresponding wholly or in part to one constraint identified in the literature review. The survey was made up of three sections which contained the dependant variables. Table 2 shows the list of questions with corresponding constraint and type. The first section of survey items gathered demographic information including postal codes, age, family income, ethnicity, health status (perceived as well as objective). The second section was a combination of multiple choice or Likert-type items asking about specific individual 
and task constraints. Options for non-response were also given for most questions, as research has shown that this can reduce the ambiguity of a neutral response [30,31]. Due to the length of the survey, and to facilitate reliability analysis, Likert scale was used to enhance the flow of completion. The third section was comprised of environmental constraint questions, phrased to allow respondents to report their likelihood of participation in sport in certain conditions, and their perceptions of their own neighborhoods. The outcome variable of regular sport participation was set on a 5-point Likert scale from Strongly Agree to Strongly Disagree. The final section allowed respondents the opportunity to enter their name and contact information in for potential recruitment in follow-up qualitative research.

Table 1: Constraints from literature review and expert panel.

\begin{tabular}{|c|c|c|c|}
\hline Constraint & Model & Defined as & Newell's (1986) \\
\hline Accessibility issues $^{1}$ & $\mathrm{E}$ & Structural & Environmental \\
\hline Poor air quality ${ }^{2}$ & None & - & Environmental \\
\hline Lack of facilities ${ }^{3,4,5}$ & E/ None & $\begin{array}{c}\text { Struct: Phys } \\
\text { Env }\end{array}$ & Environmental \\
\hline $\begin{array}{l}\text { Lack of family } \\
\text { support }^{2,4,6}\end{array}$ & E/ None & Interpersonal & Environmental \\
\hline Lack of friends ${ }^{7}$ & None & - & Environmental \\
\hline Lack of opportunity ${ }^{4}$ & None & - & Environmental \\
\hline Lack of peer support ${ }^{7}$ & None & - & Environmental \\
\hline $\begin{array}{l}\text { Neighborhood } \\
\text { features }^{3,8}\end{array}$ & E/None & $\begin{array}{c}\text { Struct: Phys } \\
\text { Env }\end{array}$ & Environmental \\
\hline $\begin{array}{l}\text { Low Parental } \\
\text { education level }{ }^{9}\end{array}$ & None & - & Environmental \\
\hline Peer influence ${ }^{10}$ & $\mathrm{E}$ & Intrapersonal & Environmental \\
\hline Small population size $\mathrm{e}^{11}$ & $\mathrm{H}$ & Structural & Environmental \\
\hline $\begin{array}{l}\text { Presence of children in } \\
\text { the family }{ }^{12}\end{array}$ & None & - & Environmental \\
\hline $\begin{array}{l}\text { Presence of facilities/ } \\
\text { opportunity } 2,3,13\end{array}$ & E/None & $\begin{array}{c}\text { Struct: Phys } \\
\text { Env }\end{array}$ & Environmental \\
\hline \begin{tabular}{|l|} 
Residential \\
location $^{2,8,11}$ \\
\end{tabular} & None/H & Structural & Environmental \\
\hline $\begin{array}{l}\text { Lower } \\
\text { socioeconomic } \\
\text { status }\end{array}$ & None/H & Structural & Environmental \\
\hline Social norms ${ }^{14}$ & None & - & Environmental \\
\hline Social support ${ }^{6}$ & $\mathrm{E}$ & Interpersonal & Environmental \\
\hline $\begin{array}{l}\text { Lack of } \\
\text { transportation }^{2}\end{array}$ & None & - & Environmental \\
\hline Weather ${ }^{15}$ & None & - & Environmental \\
\hline $\begin{array}{l}\text { Sport is not } \\
\text { important }{ }^{4}\end{array}$ & None & - & Environmental \\
\hline $\begin{array}{l}\text { High family } \\
\text { commitment }\end{array}$ & None & - & Environmental \\
\hline
\end{tabular}

\begin{tabular}{|c|c|c|c|}
\hline $\begin{array}{l}\text { Neighborhood } \\
\text { perceptions }{ }^{8,11}\end{array}$ & None & - & Environmental \\
\hline Not in my culture ${ }^{4}$ & None & - & Environmental \\
\hline Poor body image ${ }^{14}$ & None & - & Individual \\
\hline Body type $^{18}$ & None & - & Individual \\
\hline $\begin{array}{l}\text { Presence of chronic } \\
\text { illness/physical im- } \\
\text { pairment }^{1}\end{array}$ & E & Interpersonal & Individual \\
\hline Date of birth ${ }^{9}$ & None & - & Individual \\
\hline $\begin{array}{l}\text { Presence of develop- } \\
\text { mental disability }{ }^{1}\end{array}$ & E & Interpersonal & Individual \\
\hline Gender norms ${ }^{19}$ & None & - & Individual \\
\hline Gender role ${ }^{19}$ & None & - & Individual \\
\hline $\begin{array}{l}\text { I feel "gross" when I } \\
\text { engage in sport" }\end{array}$ & None & - & Individual \\
\hline $\begin{array}{l}\text { Having many } \\
\text { individual } \\
\text { responsibilities }^{17,20}\end{array}$ & None & - & Individual \\
\hline No interest in sport ${ }^{9,17}$ & None & - & Individual \\
\hline Lack of energy ${ }^{4}$ & None & - & Individual \\
\hline Lack of motivation ${ }^{20}$ & None & - & Individual \\
\hline Lack of time $\mathrm{e}^{9,20}$ & None & - & Individual \\
\hline No interest ${ }^{9}$ & None & - & Individual \\
\hline Not fun 7 & None & - & Individual \\
\hline $\begin{array}{l}\text { Low perceived } \\
\text { competence }^{6,7}\end{array}$ & None/E & Intrapersonal & Individual \\
\hline $\begin{array}{l}\text { Low perceived } \\
\text { wellness }^{9}\end{array}$ & None & - & Individual \\
\hline $\begin{array}{l}\text { Perceived } \\
\text { appearance }^{20}\end{array}$ & None & - & Individual \\
\hline Low self esteem ${ }^{21}$ & $\mathrm{H}$ & Interpersonal & Individual \\
\hline Low self-efficacy ${ }^{20}$ & None & - & Individual \\
\hline Self-perception ${ }^{14}$ & None & - & Individual \\
\hline Competitiveness $^{7}$ & None & - & Task \\
\hline Dress code ${ }^{4}$ & None & - & Individual \\
\hline Strength $^{22}$ & & & Individual \\
\hline Type of sport ${ }^{22}$ & & & Individual \\
\hline Goals of Sport ${ }^{22}$ & & & Task \\
\hline Agility 22 & & & Task \\
\hline Perseverance $^{22}$ & & & Task \\
\hline \multicolumn{4}{|c|}{$\begin{array}{l}\text { E = Environmental; H= Hierarchical; }{ }^{1} \text { Bedell., et al. } 2013 ;{ }^{2} \text { Lopt- } \\
\text { son., et al. 2012; }{ }^{3} \text { Karjalainen, 2016; }{ }^{4} \text { Kubayi, } 2015 ;{ }^{5} \text { Deelen., et } \\
\text { al. 2017; }{ }^{6} \text { Eime., et al. } 2015 ;{ }^{7} \text { Yungblut., et al. } 2012 ; ;{ }^{8} \text { Nichol, } 2009 ; \\
{ }^{9} \text { Heritage Canada, } 2013 ; ;{ }^{10} \text { Eime., et al. } 2016 ; ;{ }^{11} \text { Harrington., et } \\
\text { al.2017; }{ }^{12} \text { Downward and Rasciute, } 2015 ;{ }^{13} \text { Fuller; }{ }^{14} \text { Amusa; } \\
{ }^{15} \text { Muhajarine; }{ }^{16} \text { Sukys; }{ }^{17} \text { Faulkner; } \\
{ }^{18} \text { Tremblay; } \\
{ }^{19} \text { Robbins, 2009; }{ }^{20} \text { Robbins, 2004; }{ }^{21} \text { Raymore., et al. }{ }^{22} \text { Expert } \\
\text { Panel }\end{array}$} \\
\hline
\end{tabular}


Operationalizing sport participation as an outcome was based on data from Statistics Canada which indicates actual total sport participation [32]. Sport participation is often included as part of physical activity in Canadian literature and as such, the target of the Canadian Physical Activity Guidelines is total physical activity, which includes sport and recreation that is of moderate to vigorous intensity [33]. Therefore, the outcome variable of sport participation was based on Clark [34], which used General Social Survey (GSS) data to show that Canadian adolescent girls participate in sport approximately 2.7 times per week. It was worded as "I participate in sport regularly (3 times a week or more)".

Upon completion of the item bank, readability levels were calculated electronically. The readability of the items and survey instructions was found to be at the Grade 6 level (readers aged 10 - 11 years) which was appropriate for the intended population and would not exclude potential participants who were below the reading level for their age.

\section{Validity measures}

Having been generated from peer-reviewed literature, the constraints used for the construction of this survey were found to have construct validity. In addition, content validity was determined by the expert panel through consensus building. This qualitative method of validating content validity has been used previously in similar scenarios where time and resources are limited [35]. Also, it has been shown that engaging stakeholders in contributing to the development of research materials can increase validity [36].

The expert panel and contributors made minor revisions within each category of constraints but agreed that the questions were sufficiently clear and relevant. Changes were made to two questions to reflect the needs of our sample with respect to verbiage and confidentiality, and one change was made for clarity. The wording of the response categories to the question "How would you describe your body type" included overweight, slightly overweight, just right, slightly underweight, underweight, and I don't know. The 'neutral' category was changed to "average" with input from one of the leaders at GIRLS Inc, who indicated that the organization does not endorse a "correct" body type and that the phrase "just right" was incongruent with their values. The second change related to limiting the postal code to the first three letters (Forward Sortation Area (FSA)). This change still allows objective measures related to proximity to facilities and access to transportation and walking paths. This is relevant because research has shown that the availability of facilities to practice sport is a constraint to participation for some adolescents $[5,37,38]$. Finally, one question pertaining to the task constraint of perseverance was reworded for clarity and to reflect the purpose of the study at the suggestion of two experts.
The original statement of I always do my best in sport was changed to When something slows down or prevents my participation in sport, I do my best to resolve the issue to the satisfaction of the entire panel. In addition to these three specific changes, the DCDSB requested that questions that require a response have a non-response option made available, thus I don't know, and Not Applicable options were added to all questions as appropriate. Universal agreement with the final survey among the panelists resulted in the decision that the survey instrument had sufficient content validity to be used for the study.

\section{Discussion}

This study sought to create a new survey instrument to facilitate the examination of interactions of constraints to sport participation, and to verify the survey's validity. A critical review of the literature about constraints to sport participation for adolescent girls yielded 51 constraints, which were categorized using Newell's [25] model of constraints, and further indexed using the developmental assets profile framework [26] as a guide. Questions were created to either directly evaluate or triangulate a constraint, and thus 81 questions were developed. Due to the large quantity of variables, and because many were related to personal beliefs rather than concrete information, most questions were given in a Likert scale format. After an expert panel review and research ethics board amendments, the survey was approved for dissemination. This study demonstrated the construct and content validity of the survey.

This work has contributed a new survey instrument to the literature on constraints to sport participation. The instrument is the first to facilitate the evaluation of the multifaceted relationship between constraints, which is a major strength of this study. Individual and environmental constraints which appear most commonly in the literature on constraints to sport participation were given equal weight which was reflected in the quantity of items of each type. Task constraints, which do not typically appear in literature on constraints to sport participation were also included. When used in different geographical locations, the survey instrument may reveal the most salient constraints for that sample and elucidate which constraints interact with it. In addition, it has the potential to inform future interventions to increase sport participation at the community level. At the same time, trends may emerge on a larger scale if these community level findings are compared. Thus, the use of this survey will provide valuable knowledge regarding sport participation which in turn can be applied to future programs and policies related to sport. Specifically, information gathered on constraints to sport participation can be addressed among sport and community organizations and promote discussions regarding tailored strategies required to reduce the constraints found. 
Table 2: Survey questions with corresponding constraint and constraint type.

\begin{tabular}{|c|c|c|}
\hline Survey Question & Constraint & Constraint Type \\
\hline \multicolumn{3}{|l|}{ 1. Consent } \\
\hline \multicolumn{3}{|l|}{ 2. How did you hear about this study? } \\
\hline $\begin{array}{l}\text { 3. Please enter the first three letters of your postal code (example: } \\
\text { A1A) }\end{array}$ & SES, Population size & Environmental \\
\hline 4. What most accurately describes your ethnic background? & Ethnicity & Individual \\
\hline 5. In what year were you born? & Date of birth & Individual \\
\hline 6. In what country were you born? & Immigrant status & Individual \\
\hline $\begin{array}{l}\text { 7. If you were NOT born in Canada, in which year did you immigrate } \\
\text { to Canada? (Leave blank if you were born in Canada) }\end{array}$ & Immigrant status & Individual \\
\hline $\begin{array}{l}\text { 8. If one or both of your parents were not born in Canada, in which } \\
\text { year did they immigrate to Canada? }\end{array}$ & Immigrant status of Parents & Environmental \\
\hline $\begin{array}{l}\text { 9. Including yourself, how many children under the age of } 18 \text { live at } \\
\text { your home? }\end{array}$ & Presence of children in the family & Environmental \\
\hline 10. Of those, how many children are under the age of $5 ?$ & Presence of children in the family & Environmental \\
\hline 11. What is your birth order? & & Individual \\
\hline $\begin{array}{l}\text { 12. Have you been diagnosed with any of the following chronic } \\
\text { conditions? }\end{array}$ & $\begin{array}{c}\text { Perceived Wellness: presence of } \\
\text { illness/impairment/developmental } \\
\text { disability }\end{array}$ & Individual \\
\hline $\begin{array}{l}\text { 13. Has anybody in your immediate family been diagnosed with any } \\
\text { of the following chronic conditions? }\end{array}$ & $\begin{array}{c}\text { Perceived Wellness: family history of } \\
\text { illness/impairment/developmental } \\
\text { disability }\end{array}$ & Environmental \\
\hline 14. I use an assistive device/mobility aid regularly & Perceived Wellness & Individual \\
\hline $\begin{array}{l}\text { 15. If you answered "yes", does the assistive device/mobility aid } \\
\text { prevent you from accessing sport facilities or participating in sport? }\end{array}$ & Perceived Wellness & Individual \\
\hline 16. What is your approximate weight? (in pounds) & Body Type & Individual \\
\hline 17. What is your approximate height? (in feet/inches e.g. $5^{\prime} 7^{\prime \prime}$ ) & Body Type & Individual \\
\hline 18. How would you describe your body type? & Body Type, Body Image & Individual \\
\hline 19. How satisfied are you with your body type? & Body Type, Perceived appearance & Individual \\
\hline 20. How would you describe your overall health? & Perceived Wellness & Individual \\
\hline 21. What is your family's annual household income? & SES & Environmental \\
\hline $\begin{array}{l}\text { 22. What is your mother's/primary guardian's highest level of } \\
\text { education? }\end{array}$ & Parental education level & Environmental \\
\hline 23. What is your father's/guardian's highest level of education? & Parental education level & Environmental \\
\hline $\begin{array}{l}\text { 24. Are you currently employed? If so, how many hours per week } \\
\text { do you work? }\end{array}$ & Individual responsibilities & Individual \\
\hline $\begin{array}{l}\text { 25. Do you have daily responsibilities apart from school work? } \\
\text { Select all that apply. }\end{array}$ & Individual responsibilities & Individual \\
\hline $\begin{array}{l}\text { 26. On average, how many hours per week do you spend on these } \\
\text { responsibilities? }\end{array}$ & Individual responsibilities & Individual \\
\hline 27. I enjoy sports. & Interest & Individual \\
\hline
\end{tabular}




\begin{tabular}{|c|c|c|}
\hline 28. I participate in sport regularly (three times a week or more) & OUTCOME VARIABLE & \\
\hline 29. I have friends who I can participate in sports with. & Lack of friends & Environmental \\
\hline 30. My friends encourage me to participate in sports. & Lack of peer support & Environmental \\
\hline $\begin{array}{l}\text { 31. Having friends to participate with makes me more willing to } \\
\text { participate. }\end{array}$ & Peer influence & Environmental \\
\hline 32. I am good at the sports I enjoy. & Perceived competence & Environmental \\
\hline 33. I have had the opportunity to try different sports at school. & $\begin{array}{l}\text { Lack of opportunity, presence of facil- } \\
\text { ity/opportunity }\end{array}$ & Environmental \\
\hline $\begin{array}{l}\text { 34. I have had the opportunity to try different sports on my own } \\
\text { time, outside of school. }\end{array}$ & $\begin{array}{l}\text { Lack of opportunity, presence of facil- } \\
\text { ity/opportunity }\end{array}$ & Environmental \\
\hline 35. Members of my family participate in sport regularly. & Family commitment & Environmental \\
\hline 36. My family supports my participation in sports. & Lack of family support & Environmental \\
\hline $\begin{array}{l}\text { 37. If you answered } 1 \text { or } 2 \text {, please state the most common reason } \\
\text { for why your family does not support you participating in sport. } \\
\text { *used for qualitative analysis. }\end{array}$ & Lack of family support & Environmental \\
\hline 38. In my culture, it is expected that girls participate in sports. & Not in my culture & Environmental \\
\hline 39. I feel confident when I participate in sports. & Self esteem, self efficacy & Individual \\
\hline $\begin{array}{l}\text { 40. I believe that participating in sports will make me a healthy } \\
\text { adult. }\end{array}$ & Social norms, social support & Individual \\
\hline 41. I believe that participating in sport is fun. & Not fun & Individual \\
\hline 42. I believe that participating in sport is important. & Sport is not important & Individual \\
\hline 43. I have energy to participate in sports. & Lack of energy & Individual \\
\hline 44. I have time to participate in sports. & Lack of time & Individual \\
\hline 45. I feel comfortable with the dress code of my preferred sport. & Dress code & Individual \\
\hline $\begin{array}{l}\text { 46. My family/I can afford to participate in the sports of my } \\
\text { choosing. }\end{array}$ & SES (Financial) & Environmental \\
\hline 47. Girls should participate in sports. & Social norms & Environmental \\
\hline 48. There are certain sports in which girls should NOT participate. & Social norms & Environmental \\
\hline $\begin{array}{l}\text { 49. If you answered } 4 \text { or } 5 \text { in the previous question, please list the } \\
\text { sports in which girls should NOT participate. *used for qualitative } \\
\text { analysis. }\end{array}$ & & Individual \\
\hline 50. Sport makes me feel positive. & Self esteem & Individual \\
\hline 51. I feel gross when I participate in sports. & Feel gross & Individual \\
\hline 52. I strive to excel in the sports that I play. & Perseverance, Motivation & Individual \\
\hline 53. Sport helps girls develop into strong women. & Social norms & Environmental \\
\hline 54. Participating in sport is viewed as important in society. & Social norms, sport is important & Environmental \\
\hline 55. Most people I know agree that SP is important. & Sport is important & Environmental \\
\hline $\begin{array}{l}\text { 56. Participating in sports will help me be successful in other } \\
\text { avenues of life. }\end{array}$ & Personal goals & Individual \\
\hline $\begin{array}{l}\text { 57. When something slows down or prevents my participation in } \\
\text { sport, I always try my best to resolve the issue. }\end{array}$ & Perseverance & Individual \\
\hline 58. Which sports do you participate in? & Type of sport & Individual \\
\hline
\end{tabular}




\begin{tabular}{|c|c|c|}
\hline 59. Which sports would you participate in if you could? & Type of sport & Individual \\
\hline $\begin{array}{l}\text { 60. Which sports (if any) would you have NO INTEREST in } \\
\text { participating in? }\end{array}$ & Interest in sport, Type of sport & Individual \\
\hline $\begin{array}{l}\text { 62. Have you ever had a negative experience while practicing sport } \\
\text { which caused you to stop practicing that sport? }\end{array}$ & Interest in sport & Individual \\
\hline $\begin{array}{l}\text { 63. Please rate the degree to which these characteristics describe } \\
\text { you. }\end{array}$ & & Individual \\
\hline Assertive & & Individual \\
\hline Physically Strong & Strength & Individual \\
\hline Shy & & Individual \\
\hline Flexible/Agile & Agility & Individual \\
\hline Energetic & Have energy/endurance & Individual \\
\hline Studious & & Individual \\
\hline Creative & & Individual \\
\hline Careful & & Individual \\
\hline High Speed & Physical speed & Individual \\
\hline \multicolumn{3}{|l|}{$\begin{array}{l}\text { 64. Please rate how likely you are to participate in a sport which is/ } \\
\text { has/requires: }\end{array}$} \\
\hline Highly competitive & Competition/Recreational & Task \\
\hline Recreational & Competition/Recreational & Task \\
\hline Physically intense & Intensity of sport & Task \\
\hline Strict Rules & Rules, Type of sport & Task \\
\hline Boys and Girls On Same Team & Co-ed & Task \\
\hline Contact With Other Players & Contact sport, Type of sport & Task \\
\hline Games of long duration & Long games, Type of sport & Task \\
\hline 65. My neighborhood is safe. & Neighborhood perception & Environmental \\
\hline $\begin{array}{l}\text { 66. The outdoor air quality in my neighborhood prevents me from } \\
\text { participating in outdoor sport. }\end{array}$ & Air quality & Environmental \\
\hline 67. I am proud of where I live. & Neighborhood perception (pride) & Environmental \\
\hline $\begin{array}{l}\text { 68. There is a lot of green space (eg. parks, paths, fields) in my } \\
\text { neighborhood. }\end{array}$ & Neighborhood features & Environmental \\
\hline 69. The sidewalks and walking paths in my neighborhood are safe. & Neighborhood features & Environmental \\
\hline $\begin{array}{l}\text { 70. The weather in my geographical area allows me to participate } \\
\text { in my chosen sport when I want to. }\end{array}$ & Weather & Environmental \\
\hline $\begin{array}{l}\text { 71. The weather in my geographical area prevents me from } \\
\text { participating in my chosen sport when I want to. }\end{array}$ & Weather & Environmental \\
\hline $\begin{array}{l}\text { 72. Please rate how the following weather conditions negatively } \\
\text { affect your participation in your preferred sports. }\end{array}$ & & Environmental \\
\hline Cold temperature & Weather & Environmental \\
\hline Hot temperature & Weather & Environmental \\
\hline Humidity & Weather & Environmental \\
\hline Rain & Weather & Environmental \\
\hline Snow & Weather & Environmental \\
\hline
\end{tabular}




\begin{tabular}{|l|c|c|}
\hline $\begin{array}{l}\text { 73. I have options for where to participate when weather } \\
\text { conditions change (e.g. indoor running track/soccer pitch) }\end{array}$ & Lack of facilities & Environmental \\
\hline $\begin{array}{l}\text { 74. There is safe public transportation available for me to access } \\
\text { sport opportunities. }\end{array}$ & Transportation & Environmental \\
\hline $\begin{array}{l}\text { 75. There are safe places close to my home where I can participate } \\
\text { in or practice sport. }\end{array}$ & Lack of opportities & Environmental \\
\hline $\begin{array}{l}\text { 76. The sport facilities close to my home offer sports and activities } \\
\text { that I want to participate in. }\end{array}$ & Transportation & Environmental \\
\hline $\begin{array}{l}\text { 77. What mode of transportation do you most often use to access } \\
\text { the sport of your choice? }\end{array}$ & Transportation & Environmental \\
\hline $\begin{array}{l}\text { 78. Please enter the amount of time in minutes that it takes you to } \\
\text { get to your sport/activity of choice. }\end{array}$ & Lack of facility & Environmental \\
\hline 79. The sport facilities close to my home are clean. & Lack of facility & Environmental \\
\hline 80. The sport facilities close to my home are accessible. & Environmental \\
\hline 81. The sport facilities close to my home are not over-crowded &
\end{tabular}

Recommendations for follow-up studies should involve administering the survey to a larger sample size in order to establish testretest reliability and factor analysis. Given the standard sample size calculation of 10 participants for each construct or question, a sample size of approximately 800 participants is suggested for future research. At the same time, future studies should focus on recruitment strategies tailored to adolescent populations. Robbins., et al. [39] suggest that older adolescents may lack interest in participating in this type of research because of an already declining interest in physical activity. This has been substantiated in more recent work as well, as lack of interest is a common theme in adolescent girls' approach to sport participation $[1,19,40]$.

To increase response rate, the survey may be shortened from its original 20 - 25 minute completion time to a slightly shorter 10 - 20 minutes as suggested in previous literature [41]. Also, the survey could be delivered cyclically, at different semesters and with more advanced preparation. This may increase compliance among educators who are the gatekeepers to the participant pool, and who often have curriculum material to deliver which is planned well in advance. Adding questions to clarify frequency, intensity and times of year that sport participation is taking place can also aid in delineating between sport and physical activity, as has been suggested in recent work by Allison and colleagues [42] as a way of increasing the quality of data to better inform future interventions.

\section{Conclusion}

Though much knowledge exists on the topic of specific constraints to sport participation for this population, there is a need for this knowledge to be mobilized into practice so that adolescent girls can reap the benefits of participating in sports. The development of a measurement tool to assess interactions between constraints to sport participation among adolescent girls is a key step in addressing these constraints. The information gathered from this survey may aid in understanding the interactions among constraints and address challenges faced among adolescent girls. This will inform future sport initiatives and encourage further discussions regarding the constraints faced in sport. It is necessary to administer this tool again using a larger sample to establish test-retest reliability, reduce the possibility of Type I error, and to refine some of the items to elicit more responses. Overall this tool demonstrated good construct and content validity based on expert panel review. With some changes as outlined above, it can be administered to a larger sample of adolescent girls to assess interactions among constraints to sport participation. Thus, the use of this survey in various sectors will address constraints to sport participation, which in turn can aid in developing future strategies to promote overall participation in sport. 


\section{Acknowledgement}

Special thanks to Dr. Shilpa Dogra and Dr. Nick Wattie for their guidance and support.

\section{Conflict of Interest}

The authors declare no conflict of interest. This study was funded in part by Women's XChange 15K at Women's College Hospital in Toronto.

\section{Ethics Approval}

This study received ethics approval from the University of Ontario Institute of Technology Research Ethics Board.

\section{Bibliography}

1. Heritage Canada. "Sport participation 2010 research paper" (2013).

2. Bélanger MCM Sabiston and T Barnett. "Number of years of participation in some, but not all, types of physical activity during adolescence predicts level of physical activity in adulthood: Results from a 13-year study". International Journal of Behavioral Nutrition and Physical Activity 12 (2015): 76.

3. Howie E K., et al. "Organized Sport Trajectories from Childhood to Adolescence and Health Associations". Medicine and Science in Sports and Exercise 48 (2016): 1331-1339.

4. Eime R M., et al. "The relationship of sport participation to provision of sports facilities and socioeconomic status: A geographical analysis". Australian and New Zealand Journal of Public Health 41 (2017): 248-255.

5. Karjalainen A., et al. "Multi-dimensional interacting constraints on physical activity behaviours in the finish population". Sports Medicine 46 (2016): 969-976.

6. Kubayi N A. "Female Sport Participation In South African Rural Schools: Analysis Of Socio-Cultural Constraints". European Review of Applied Sociology 8 (2015): 6-10.

7. Deelen I., et al. "Do objective neighbourhood characteristics relate to residents' preferences for certain sports locations? A cross-sectional study using a discrete choice modelling approach". BMC Public Health 17 (2017): 943.
8. Harrington DW., et al. "Parents' perceived barriers to accessing sports and recreation facilities in Ontario, Canada: Exploring the relationships between income, neighbourhood deprivation, and community". International Journal of Environmental Research and Public Health 14 (2017): 1272.

9. Tannehill D., et al. "What young people say about physical activity: the Children's Sport Participation and Physical Activity (CSPPA) study”. Sport 4 (2015): 442-462.

10. Yungblut H E., et al. "On physical activity during early adolescence". Journal of Sports Science and Medicine 11 (2012).

11. Allender S., et al. "Understanding participation in sport and physical activity among children and adults: a review of qualitative studies". Health Education Research 21 (2006): 826-835.

12. Visek A J., et al. "The fun integration theory: toward sustaining children and adolescents sport participation". Journal of Physical Activity and Health 12 (2015): 424433.

13. Amusa, L O., et al. "Perceived barriers to sport and recreation participation in Botswana". African Journal for Physical Health Education 2 (2008): 115-129.

14. Vasudevan V., et al. "Development of the barriers to physical activity questionnaire for people with mobility impairments". Disability and Health Journal 8 (2015): 547556.

15. Alexandris $\mathrm{K}$ and B Carroll. "Demographic differences in the perception of constraints on recreational sport participation: Results from a study in Greece". Leisure Studies 16 (1997): 107-125.

16. Raymore L A., et al. "Self-esteem, gender, and socioeconomic status: Their relation to perceptions of constraint on leisure among adolescents". Journal of Leisure Research 26 (1994): 99-118. 
17. Rodrigues I B., et al. "Development and validation of a new tool to measure the facilitators, barriers and preferences to exercise in people with osteoporosis". BMC Musculoskeletal Disorders 18 (2017): 540.

18. Siesmaa E J., et al. “Measuring children's self-reported sport participation, risk perception and injury history: Development and validation of a survey instrument". Journal of Science and Medicine in Sport 14 (2011): 22-26.

19. Charlton A., et al. "Barriers to participation: Analysis to inform the development of the 2010/11 Taking Part Survey". London (2010).

20. Crawford D W., et al. "A hierarchical model of leisure constraints". Leisure Sciences 13 (1991): 309-320.

21. Gyurcsik N C., et al. "An ecologically based examination of barriers to physical activity in students from grade seven through first-year university". Journal of Adolescent Health 38 (2006): 704-711.

22. Bronfenbrenner U. "Toward an experimental ecology of human development". American Psychologist 32 (1977): 513.

23. Alexandris K., et al. "Perceived constraints on recreational sport participation: Investigating their relationship with intrinsic motivation, extrinsic motivation and amotivation". Journal of Leisure Research 34 (2002): 233-252.

24. McArthur D., et al. "Factors influencing adherence to regular exercise in middle-aged women: a qualitative study to inform clinical practice". BMC Women's Health 14 (2014): 49.

25. Newell K M. Constraints on the development of coordination. "Motor development in children: Aspects of coordination and control". (1986): 341-360.

26. Scales P C. "Reducing risks and building developmental assets: Essential actions for promoting adolescent health". Journal of School Health 69 (1999): 113-119.

27. Lerner RM., et al. "Exemplifying the Integrations of the Relational Developmental System: Synthesizing Theory, Research, and Application to Promote Positive Development and Social Justice". Journal of Adolescent Research 23.3 (2008): 245-255.
28. Zamanzadeh V., et al. "Design and implementation content validity study: development of an instrument for measuring patient-centered communication". Journal of Caring Sciences 4 (2015): 165.

29. Moher D., et al. "Preferred reporting items for systematic reviews and meta-analyses: The PRISMA statement". PLoS Medicine 6 (2009): e1000097.

30. Chyung S Y., et al. "Evidence-based survey design: The use of a midpoint on the Likert scale". Performance Improvement 56 (2017): 15-23.

31. Kulas J T., et al. "Middle response functioning in Likert-responses to personality items". Journal of Business and Psychology 22 (2008): 251-259.

32. Statistics Canada. "Visible minority of person" (2015).

33. Sharratt M T and W E Hearst. "Canada's physical activity guides: background, process, and development". (2007).

34. Clark W. “Kids' sports”. Canadian Social Trends 85 (2008): 5461.

35. Presser S., et al. "Methods for testing and evaluating survey questions". Public Opinion Quarterly 68 (2004): 109-130.

36. Jacquez F., et al. "Youth as partners, participants or passive recipients: A review of children and adolescents in community-based participatory research (CBPR)". American Journal of Community Psychology 51 (2013): 176-189.

37. Fuller D., et al. "School sports opportunities influence physical activity in secondary school and beyond". Journal of School Health 81 (2011): 449-454.

38. Loptson K., et al. "Walkable for whom? Examining the role of the built environment on the neighbourhood-based physical activity of children". Canadian Journal of Public Health 103 (2012): S29-S34.

39. Robbins L B., et al. "Physical activity self-definition among adolescents". Research and Theory for Nursing Practice 18 (2004): 317-330. 
40. Faulkner G., et al. "Canadian 24-Hour Movement Guidelines for Children and Youth: Exploring the perceptions of stakeholders regarding their acceptability, barriers to uptake, and dissemination". Applied Physiology 6 (2016): S303-S310.

41. Revilla M and C Ochoa. "Ideal and maximum length for a web survey". International Journal of Market Research 59 (2017): 557-565.

42. Allison R., et al. "Is team sport the key to getting everybody active, every day? A systematic review of physical activity interventions aimed at increasing girls' participation in team sport”. AIMS Public Health 4 (2017): 202.

43. Bedell G., et al. "Community participation, supports, and barriers of school-age children with and without disabilities". Archives of Physical Medicine and Rehabilitation 94 (2013): 315323.

44. Downward P and S Rasciute. "Exploring the covariates of sport participation for health: an analysis of males and females in England". Journal of Sports Sciences 33 (2015): 67-76.

45. Eime R M., et al. "Socioecological factors potentially associated with participation in physical activity and sport: A longitudinal study of adolescent girls". Journal of Science and Medicine in Sport 18 (2015): 684-690.

46. Muhajarine N., et al. "Longitudinal active living research to address physical inactivity and sedentary behaviour in children in transition from preadolescence to adolescence". BMC Public Health 15 (2015): 495.

47. Nichol M E., et al. "Associations between school recreational environments and physical activity". Journal of School Health 79 (2009): 247-254.

48. Sukys S., et al. "Do Parents' Exercise Habits Predict 13-18-YearOld Adolescents' Involvement in Sport?". Journal of Sports Science and Medicine 13 (2014): 522.

Volume 3 Issue 6 June 2021

(c) All rights are reserved by Irmina Klicnik., et al. 